\title{
Welfare States' Social Investment Strategies and the Emergence of Dutch Experiments on a Minimum Income Guarantee
}

\author{
Loek Groot*, Ruud Muffels** and Timo Verlaat*** \\ *Utrecht University School of Economics, The Netherlands \\ E-mail: L.F.M.Groot@uu.nl \\ **Department of Sociology, Tilburg University, The Netherlands \\ E-mail: Ruud.J.Muffels@uvt.nl \\ ***Utrecht University School of Economics, The Netherlands \\ E-mail: T.L.L.Verlaat@uu.nl
}

The focus in welfare state support in the Netherlands has been shifted from workfare and activation policies to social investment strategies. The discourse on basic income and the related municipal experiments highlights this shift. We address the inspiration found in basic income and behavioural economic and motivational psychological theoretical insights for the design of the experiments and for new avenues of minimum income protection and providing participation opportunities for the disadvantaged. The emerging new paradigm also implies a shift in the cultural values and principles on which welfare state policies are implicitly founded. This means that in these endeavours particular social values are put more upfront, such as personal autonomy (capacitating people by providing opportunities and therewith 'free choice') and trust (activating people by putting trust in their self-management capacities) which in day-to-day policy practice means more tailor-made, demand-oriented integrated mediation and coaching while rewarding people instead of penalising them.

Keywords: Basic income, workfare, trust, experiment, social assistance benefit.

\section{Introduction}

The shift from workfare and activation towards a social investment and capacitating approach to social policy in the Netherlands, without yet being implemented in actual policy practices (Hemerijck, 2013, 2017) is called an emerging policy paradigm by Morel et al. (2012). Notably, in the years following the economic crisis of 2008, under the influence of austerity macroeconomic policies to reduce government budget deficits, social policy seems to have returned to the neoliberal market-oriented welfare paradigm. Work-first and workfare principles are reinforced through a stronger monitoring and tightening of benefit access conditions, cuts in unemployment and disability benefit levels and duration and stricter law enforcement, especially for youngsters and school-leavers on social assistance (henceforth SA). Stronger law enforcement occurred notably with respect to SA beneficiaries' application obligations and reintegration duties (see also Hemerijck, 2013, 2017; Soentken et al., 2017). The ideas on basic income (henceforth BI) and the local community experiments which are currently in debate in the Netherlands can be 
seen as highlighting a shift to pursue social investment or a 'capacitating' approach to social policy. We argue that the local community experiments on a guaranteed minimum or participation income (Atkinson, 1996) which are currently in debate in the Netherlands can be seen as the product of three recent developments (1) a paradigm shift in social policymaking towards policies that pursue social investment or 'capacitating' strategies, (2) a revival of the debate on basic and participation income in the Netherlands and (3) a growing interest at national and local policy levels in behaviourally informed policies. Departing from this reasoning, we give an overview of the recent discourses on welfare state policies, culminating in the launching of local experiments having similarities with $\mathrm{BI}$ approaches to social policy. With a view to welfare state evolution it becomes apparent that since the mid 1990s attempts to replace workfare oriented policies by social investment and 'capacitating' policies are becoming more common, notably in the Scandinavian countries but also in the Netherlands (Maydell et al., 2006; Morel et al., 2012; Hemerijck, 2013, 2017). Consequently, classical activation policies that are vested on 'making work pay' are increasingly replaced by policies that create participation and integration opportunities by pro-actively investing in people's capacities or 'capabilities' (Sen, 2004, 2009). Policy makers start to realise that traditional policy instruments, e.g. monitoring and sanctions, are, apart from being costly in implementation, also not necessarily effective; for which reason they show mounting interest in alternative approaches inspired by new behavioural insights to policymaking and the testing of these policies in the field. The BI initiatives and local Participation Act experiments can be viewed as a way to test these behavioural policies and the intervention triggers needed to influence behaviour. In what follows we will set out the interplay of these institutional and ideological factors that have led to these innovative attempts to reform social policy making.

\section{Welfare states' social investment strategies}

According to many welfare state observers the post-war welfare state evolution in Europe was marked by three stages (Hemerijck, 2013; Pierson et al., 2014). The first stage, up to the 1970s, was featured by innovation and expansion in which citizens were granted comprehensive social rights. Universal rights and countercyclical welfare spending based on Keynesian demand management principles were considered salient for adjustment to recessions and employment. The second stage, during the 1980s and early 1990s, followed after inflationary pressures, caused by wage rises beyond productivity levels, mass unemployment, 'deadlock corporatism' (Hemerijck, 2013) and sluggish growth. It can be characterised as the period of contraction by way of fiscal austerity and retrenchment policies. It was also the era of monetary, supply-side economics to suppress inflation and to free markets from their collective regulation, by reducing the role of the state in favour of the market. This was done through cost-containment (retrenchment policies), privatisation (shifting responsibility from the state to the citizen) and deregulation (for example, reducing labour market rigidity through more lenient employment protection). A similar evolution took place in the Dutch welfare state resembling the institutional set-up that follows from the mainstream economists' paradigm, oriented at weak coordination, low employment protection, 'stick and carrot' type of unemployment insurance and workfare oriented labour market policies (Hemerijck, 2013, 2017). Social policies at local level resembled this neoliberal policy 
while embracing the 'stick and carrot' approach and maintaining strong access conditions to SA benefits especially. The neoliberal shift became manifest in reforms in social insurance (cutbacks in benefits, shortening of duration, tightening of access-conditions, and so on) and activating labour market policy through 'make work pay' policies (inwork benefits, tax deductions, wage subsidies), combined with stimulating social pacts to barter wage restraint to reduce inflationary pressures for employment sharing (workingtime flexibility and parental leave schemes, and so on). According to Hemerijck since the mid 1990s, a third stage set in of what he calls the 'social investment' welfare state. The term 'social investment' refers to a welfare state that is pro-active or 'enabling' in creating integration and participation opportunities to its citizens and notably to the disadvantaged. The theoretical underpinning of this third stage in the development of the welfare state is according to Hemerijck (2017) associated with inclusive growth and inclusive society concepts that stress the adverse consequences of the widening of the inequality gap between insiders and outsiders on the labour market. Hemerijck (2017) also refers to the transitional labour market approach of Günther Schmid ('making transitions pay'), flexicurity principles (the nexus of promoting flexibilisation while guaranteeing job, employment and income security) and Sen's capability theory to theoretically underpin the 'capacitating' approach (Schmid and Gazier, 2002; Sen, 2004, 2009; Muffels, 2008). We agree that these ideas might provide new avenues to social policy. In our view also behavioural economics insights and psychological motivation theories need to be added to provide a behavioural perspective to this third stage of welfare state policies according to which new avenues are explored to affect benefit recipients' behaviour. These two theoretical strands combined constitute the theoretical underpinnings of the local experiments in the Participation Act.

In the wake of the economic crisis in 2008, the underlying shift in the Netherlands to a 'capacitating' approach of social policy has not disappeared but has encountered stronger barriers to its further evolvement due to austerity policies that reduced significantly the available budgets for reintegration policies, notably at the local level. The Dutch welfare system is in the welfare regime literature conceived as a hybrid case that is strongly vested in its own corporatist and liberal roots according to which activation policies that were set in since the mid 1990s are still strongly vested in the workfare principle and a 'stick and carrot' approach to activation (Goodin et al., 1999). This means that even though we believe that the Netherlands are on their way to implementing elements of the capacitating approach, this will only gradually and not fully replace the workfare principles on which the system is grounded. The political landscape, with a new liberalChristian democratic government inaugurated in October 2017, having a small majority in Parliament and a strong opposition with some influential right-wing populist and leftwing green parties, is also not favourable to such a policy shift happening in due course. For the same reason the $\mathrm{BI}$ debate has not been very influential during the crisis years up to 2015 after which the Netherlands recovered becoming one of the fastest growing economies in the EU. However, the debate on BI exhibited a revival mainly due to the initiatives of the municipalities to start experimenting with alternative intervention strategies of reintegrating people. The investment approach hinges according to Hemerijck (2017) on three major welfare functions: stocks (raising the quality of human capital), flows (easing life-course transitions) and buffers (maintaining strong minimum-income protection). The capacitating approach therefore also implies a shift from 'making work pay' policies (workfare) to 'making transitions pay' (enabling to act) according to which 
investments in people's endowments and capabilities (human capital) would equip them with more options to act (easing transitions) or do the things which one has reason to value for their own lives. This is pursued not by disincentivising or penalising people but by capacitating and addressing people's 'intrinsic motivation' through rewarding self-initiative and supporting opportunities to act which match people's capacities and talents but which does not necessarily align immediately with workfare principles to seek fulltime paid work. In this way people are endowed with more 'free choice' and personal autonomy, which might also mean that there is more room for risk-taking and personal autonomy or self-management. For policymaking, the shift to social investment and 'enabling' would therefore also imply the pursue of social values such as personal autonomy and free-choice, but also reciprocity and trust (Muffels, 2014). The build-up of relations of trust in policy activation practices supposedly pays-off in the form of skills upgrading and productivity gains but also in improving people's health and subjective well-being.

\section{Decentralised social assistance and the Participation Act of 2015}

To explain the recent plethora of local initiatives to launch, 'basic income inspired' field experiments, it is instructive to give a short account of the peculiar institutional setting of providing minimum income SA in the Netherlands. To give some idea of the scale of the emergence of initiatives for such local field experiments, in early 2017 more than forty municipalities, including major cities such as Tilburg, Groningen, Amsterdam and Utrecht, were seriously considering a Bl-inspired field experiment. Although similar local initiatives can be found worldwide, e.g. in USA, Scotland, Canada, Italy and France (McFarland, 2017), these are rather rare or exceptional cases, like the private $Y$ Combinator initiative in the USA. In this section, we provide two clues to explain the avalanche of local initiatives observed in the Netherlands but not elsewhere. Firstly, the maturity of the Dutch debate on BI. Up until the turn of the century, the Netherlands was considered one of the heartlands of BI. In an earlier publication, the Dutch debate was described as a peat fire, occasionally fuelled when the unemployment rate increased and extinguished when unemployment went down, as in the period of the so called 'Dutch miracle' at the turn of the century. While unemployment is currently going down although not for the least advantaged, such as the low skilled and older unemployed worker, the BI debate stays vivid, suggesting that the fire will continue to be fuelled. Three stages were being followed in the Netherlands to get $\mathrm{BI}$ on the agenda: '(1) the royal way: arguing for a full and avowedly unconditional basic income, by 'decoupling of income from work'; (2) arguing for a partial basic income, as the linchpin of a problem-solving social engineering strategy; finally, (3) the strategy of bringing in basic income by the support of measures that are not associated with the notion of unconditionality, but in practice serve to loosen the link between income and paid work. This strategy we have called 'implementation by stealth' (Groot and Van der Veen, 2000: 216). The Dutch debate went through these stages more or less sequentially. In the aftermath of the crisis the voices on BI fell silent because policy concentrated on maintaining employment and reducing budget deficits through austerity measures. The recent initiatives to launch $\mathrm{BI}$ inspired experiments may be considered as a fourth stage or strategy, with its own merits, limitations and dangers (see also Groot (2004) and Widerquist (forthcoming)). 
The second clue concerns the incentives arising from the institutional organisation of the disbursement of SA. Like many other European countries, the Dutch welfare state provides a last resort conditional minimum income guarantee. It is conditional in the sense that it is means-tested and subject to several willingness-to-work tests (e.g. recipients must write application letters at regular intervals, subscribe to temp-agencies for work and be prepared to accept available rather than suitable job offers). One of the peculiar features of the Dutch system is that the level of the SA benefit is related to the level of the statutory minimum wage: a single person household on welfare receives 70 per cent of the minimum wage, whereas a couple, due to economics of scale in consumption, is entitled to 100 per cent of the minimum wage. ${ }^{1}$ The statutory minimum wage can be considered as the Archimedean point in the income distribution. Almost all welfare benefits, ranging from the unconditional child benefits and statutory old age retirement benefits, as well as conditional unemployment and SA benefits are linked to the minimum wage. The adjustment of minimum wage levels over time in turn is written into law (the Wet Koppeling met Afwijkingsmogelijkheid), with the effect that, barring economic shocks or excessive wage demands by trade unions, if wages increase economy-wide, then the statutory minimum wage increases automatically by the same percentage. Through the linkage of the minimum wage to the overall wage in the economy, and the linkage of welfare benefits to the minimum wage, most incomes in the Dutch economy move in tandem: if the economy is booming and wages go up, the minimum wage and welfare benefits rise approximately in the same proportion.

Even more important is that since 2001 the disbursement of SA benefits is fiscally decentralised from the central state to the local level, whereas before 2001 all local expenditures on SA were reimbursed by the central government. By and large the budgets municipalities receive to provide SA are now based on a complicated population formula and not related to the actual expenditures on SA. So budgets received can be considered as lump sum and based on objective population parameters, while expenditures are dependent on local policies and regional labour markets. According to economic theory, fiscal decentralisation will give local governments an incentive to reduce the SA caseload and to better adjust their policies to local preferences. However, one major drawback is that the decentralisation also had the effect that more use is made of the still centrally administered social insurance benefits. In particular, the disability insurance scheme for the young (Wajong) saw a rise in caseloads after the fiscal decentralisation of the SA (Roelofs and van Vuuren, 2017).

The most recent change in the SA institutional setting took place on January 1, 2015 when the Social Assistance Act was replaced by the Participation Act. One of the changes is that people on welfare now have an even more strict duty to accept work, even if it does not fit their skills or occupational background. Another change is that recipients must be willing to commute up to three hours. But probably the most significant change is that under the new law councils have the power to specify what welfare recipients have to do in return for keeping their benefits, varying from volunteer work to insertion into local projects. Failure to fulfil these obligations under this Quid pro Quo requirement may result in benefits cuts. One concern on the welfare reform is that the new approach will prove to be bureaucratic and time-consuming. Due to the additional regulations and controls and special exemptions, the complexity of benefits claims will increase, leading to more work for case-managers. The danger is that this will lead to mistakes, with well-intentioned claimants being confronted with benefit cuts, while others cheating 
the system go unpunished. What's more, the threat of sanctions may create a conflict of interests and mistrust between case-managers and claimants, instead of a situation of trust and a sense of common interest.

For the local authorities it means that, due to the national linkage of benefits to (minimum) wages, there is no room to slightly lower benefits to provide benefit claimants a stronger incentive to take up paid work in the case that the number of vacancies rises in the local economy. From a local perspective, benefit levels are so to speak set in stone. Due to the fiscal decentralisation, the authorities still have a strong incentive to cut expenditures on SA, since any net revenues can be used for other policies or to reduce local taxes. Not being able to tinker or fiddle with benefit levels, the main instrument is to apply sanctions strictly to benefit claimants who fail to meet the requirements on job applications or participation in mandatory activation programs. To a varying degree municipalities do indeed make use of their power to implement benefit cuts or sanctions. Finally, due to the new Participation Act, the authorities have an additional instrument to activate SA recipients, namely to use the Quid pro Quo requirement for maintaining benefits: that is, to test the willingness to fulfil unpaid societal activities in return for receiving SA. However, this additional instrument also involves, likewise, a duty on the side of the municipality: the municipality must organise a variety of activities to allow recipients to fulfil their Quid pro Quo duties. Issuing sanctions only makes sense if recipients are given the real opportunity to reciprocate. Thus the Participation Act of 2015 gives municipalities more options to adhere to the neoliberal principles of workfare and to use the 'stick' of sanctions to enforce people to accept job offers and exit into paid work. Quite a few municipalities indeed implemented the new Participation Act in this strict way whereas others argued that due to the lack of employment opportunities the application of the sanctions was ineffective, while organising the Quid pro Quo duties remains challenging for municipalities. At the same time the number of beneficiaries increased rapidly during the crisis. Municipalities confronted with this rise in claimants were therefore inclined to embrace the experimentations of Article 83 of the Participation Act that came into force in 2017, which allow them to experiment with different forms of providing SA. The common denominator for these local experiments is conveying trust in the recipient' behaviour, for which reason they are called trust experiments, while the standard obligations, to regularly apply for jobs and to reintegrate into any paid work whatsoever, are waived for the duration of the experiment, which is set at a maximum of two years.

\section{The emergence of the Dutch minimum income guarantee experiments}

At the moment of writing, eight municipalities, Tilburg, Groningen, Deventer, Nijmegen, Wageningen, Apeldoorn, Oss and Epe were engaged in the setting up of these experiments, of which the first five municipalities started in the framework of the experimentations of Article 83 of the Participation Act. The other three municipalities used the room in the Participation Act to reform their implementation practices but which forbade them from relaxing the strict withdrawal rules of additional earnings which is only allowed for municipalities accepting implementation of Article 83. Most of them have in June 2018 nearly finished the recruiting of participants for their experiment, having commenced in the fall of 2017. The ninth municipality, Utrecht, started in June 2018. By the beginning of June 2018 a total of more than 3,000 SA beneficiaries are already 
participating in these experiments. In the end more than 5,000 participants are likely to be participating, consisting of about 14 per cent of the target population of SA beneficiaries in these nine cities. The SA experiments in the Netherlands can be seen as a way to shift local social policy practices into the social investment or 'capacitating' approach, because there is more room for experimenting with tailor-made, demand-oriented and intensive mediation and integrated policies (although Article 83's requirements are rather strict and do not allow for much flexibility in the design of the policy experiments). However, the basic idea is to relax the existing rules with respect to application obligations, reintegration duties, earnings withdrawal and sanctioning. The existing rules are conceived as reflecting a form of distrust, whereas the ideas underlying the experiments are based on the assumption that the building up of trust with the citizens is likely to be more effective in creating integration and participation opportunities. The experiments are also designed to improve the motivation and capabilities of the client to take up one's own responsibility (self-management), as shown by actively participating in the supervision and coaching trajectories in one of the treatments.

\section{Theoretical underpinnings of the experiments}

The local municipalities experimenting under Article 83 needed to fill in a detailed application form in which the 'policy theory' and the theoretical underpinnings of the experiment were to be set out. The hypotheses and assumptions underlying the ideas of the local experiments were also asked for in detail. These policy theories provide the theoretical underpinnings and are grounded on five insights, derived from a wide range of literatures:

- The first insight concerns recent findings on the impact of poverty on people's mind-set. Research in this relatively new field of study by Mani et al. (2013) and Mullainathan and Shafir (2013) demonstrates that (financial) scarcity and poverty stress reduces people's cognitive resources. If financial scarcity and compliance activities consume large parts of claimants' cognitive resources, little is left for other important and cognitively challenging tasks, such as job search;

- The second insight from behavioural economics concerns the role of implicit values underlying welfare state institutions and practices for behaviour, such as reciprocity and trust. Reciprocity means that individuals reward favours (positive reciprocity), while taking revenge when being harmed (negative reciprocity) (Fehr and Schmidt, 2003). Negative incentives as sanctions might not be the best way to induce cooperative and compliant behaviour. Experimental economics also showed that people in return for receiving trust tend to be extra motivated, putting more effort into their task and by doing so rewarding the truster. Trust in this way generates feelings of positive reciprocity and therewith sustained effort and increased productivity (Bohnet et al., 2001);

- The third insight stems from psychological motivation theories and refers to the observation that extrinsic incentives can crowd out intrinsic motivation (Frey and Jegen, 2001). Self-determination theory (Deci and Ryan, 1985) suggests that intrinsically motivated people engage in an activity because they find it enjoyable and interesting and because of that showing more behavioural effectiveness and persistence, and enhanced well-being (Ryan et al., 1997). The theory also states that putting trust in people generates feelings of 'self-efficacy' with salient effects on job search and sustainable employment. 
Previous research also shows that one can effectively strengthen intrinsic motivation by conveying the activity as choice rather than as control;

- The last insight also pertains to 'free choice' and refers to Sen's capability theory. In Sen's words capabilities are the choice options people are offered to do the things that they consider important for their own lives. In this way people are offered opportunities creating personal autonomy and self-confidence while enhancing well-being (Sen, 2004, 2009).

These insights shaped the design of the experiments and the definition of the treatment groups. Inspiration for these behavioural insights as a tool for social policymaking can be found in Nobel laureate Richard Thaler's ideas on nudging: that is, encouraging people to behave in their broad self-interest (Thaler and Sunstein, 2008). As explained before, similar insights also constituted the theoretical underpinnings of the third 'social investment' stage in the evolution of welfare state policies.

The local trust experiments: common features and similarities with basic income

The local experiments are called trust experiments because the initial idea was to show people more trust by exempting them from the standard application and re-integration obligations. Below we give some more detail on these experiments:

- In all experiments a shift takes place from sanctioning and penalising to rewarding effort. The withdrawal rate at which earnings are subtracted from the benefit is reduced from 100 or 75 to 50 per cent. This resembles one of the features of a BI scheme, notably of a negative income tax, according to which the $\mathrm{BI}$ is gradually taxed away. The income threshold in the experiments is implicitly set at 120 per cent of the SA level because people can earn additionally a maximum of 200 euros per month: that is, 20 per cent of the basic SA allowance for a single person.

- The focus is on safeguarding a more or less unconditional right on a minimum income and rewarding people's own efforts and initiatives, whereby the reintegration is not limited to paid fulltime work only but allows for a broader range of social integration measures and outcomes (bridge and part-time-employment; education; selfmanagement; well-being; health and social participation). The unconditionality of the income support breaks with the conditionality in the Participation Act, even though reciprocity (defined by the expectation that clients need to be motivated to participate in the experiment and to engage in participation activities) is still the leading principle in all experiments.

- Most cities acknowledge that some sort of reciprocity is needed but that this can take different forms, such as that the client shows its own-initiative, own-responsibility and efforts in improving his/her chances for work or social integration. In their views, unconditionality is not a reward for laziness but a different way of activating the client and for creating opportunities for integration. This way of tailor-made supervision and coaching better tunes with scientific insights in behavioural economics and psychological motivation theories and also seems to mirror a mature relationship between government and citizen, based on trust and common interests. Even though the reciprocity principle is maintained, the more relaxed way of monitoring clients and the willingness to keep trust in the client not misusing the SA benefit resembles another basic feature of a $\mathrm{BI}$ scheme. 
- All cities express the importance of performing evaluation research to assess the effects of the various treatments in the local experiments: not only on employment but on social integration, health, human capital and capabilities, objective and subjective well-being and quality of life outcomes. The expectation that the new way of treatment will especially also improve the motivation, health and well-being of the SA claimants resembles again the expected salient outcomes of $\mathrm{BI}$ experiments on these indicators as also illustrated in evaluation research of negative income tax (NIT) experiments in the US and Canada in the 1970s.

The design of the local experiments; the various treatments

The various treatments in the design of the local experiments share the same ideas but differ to some extent. Basically they all want to examine the effects of four separate treatments:

1. The self-management and exemption group. Participants are expected to help themselves in re-entry to work. The idea is that beneficiaries need to learn how to help themselves through acting pro-actively and with confidence: that is, through self-management. The participants are exempted from the existing application and re-integration obligations. They might (Tilburg, Nijmegen, Groningen, Deventer) or might not (Utrecht and Wageningen) be subject to the reduced withdrawal rate of earnings. In Deventer and Tilburg, participants may get an additional exit premium.

2. The earnings release group. For participants, when they find paid work, their additional earnings will be taxed at a rate of 50 per cent instead of 75 or 100 per cent in the standard case. They are to some extent exempted from the application and re-integration obligations. This group is hence rewarded for their attempts to find work and earn a living through working.

3. The tailor-made supervision group. Participants get extra support through tailor-made supervision and intensive mediation. They have more frequent contact with their (work) coach or contact person at the municipality office and the treatment of the client is demand-driven instead of supply-driven: that is, that the wishes and expectations of the client lead the content of the treatment.

4. The standard treatment group. Participants in this group get the standard treatment that was conducted in the period before the experiments started. They are of course subject to the existing strict application and re-integration obligations.

Contrary to an unconditional $\mathrm{BI}$ for everyone, the Dutch local experiments are targeted at SA recipients. The NIT experiments in the US and Canada in the late 1960s and early 1970 s also included families with low earned incomes. There are some similarities though, e.g. with respect to the chosen experimental RCT (random controlled trial) design and the choice of the treatment groups, notably the exemption and earnings release groups.

\section{Conclusions and discussion}

In this article, we argue that the launching of a variety of local experiments with minimum income guarantee in nine Dutch cities in 2017 can be explained by three 
main factors: a paradigm shift towards social investment policies, a matured societal debate on $\mathrm{BI}$ and new behavioural insights in welfare state policy-making providing also a different perspective on the reintegration of disadvantaged people in society. These three developments were accompanied by the decentralisation of the provision of SA to the local government. Apparently, the local experiments have some similarities with the $\mathrm{BI}$ ideas, which potentially provided new avenues for social policymaking (Atkinson, 1996; Van Parijs, 2004). These avenues resemble the ongoing shift in welfare state policy to give people more personal autonomy, to build up trust and to enable people to participate in society by providing opportunities and 'free choice'. The term 'social investment' or inclusive welfare state has been used pertaining to a welfare state that is pro-active and 'enabling'. The term 'trust experiments' illustrates the wish of the municipalities to depart from the workfare or 'stick and carrot' approach and to reform the treatment practices to build-up trust and providing 'free choice' to people - instead of primarily distrusting people, by strict monitoring and sanctioning practices. Insights from behavioural economics, the role of social values and capabilities, and psychological motivation theories suggest that investing in personal autonomy, trust and intrinsic motivation might pay-off in terms of people's performance and their health and subjective well-being. Whether the experiments will in the end alter the implementation practices will in our view not only depend on the outcomes of the evaluation research, which are rather narrowly formulated in Article 83, as to what extent the new approach primarily improves the transition into sustainable employment of the SA clients. The municipalities themselves have formulated a wider range of goals in which the experiments are also seen as a success when positive outcomes on health, self-management and well-being are achieved even when the primary goal of exit out of SA through reintegration into fulltime paid work has not been fully attained. The article sets out that the experiments may mark an irreversible shift in welfare state policy making in which innovative attempts to move from conditional SA to less or unconditional participation or BI approaches might be a more aligned and appropriate response to the underlying societal dynamics, to resolve the challenges of rising inequality and dualisation of the labour market with the aim of improving trust and personal autonomy and creating wider opportunities to disadvantaged people. At last, after decades of welfare policies aimed at strengthening the link between income and paid work, there is an opening to see whether the provision of SA according to features of a $\mathrm{BI}$ - attenuation of the poverty trap, exemption from duties and demand-driven tailor-made social investments - are worthwhile to consider for future policy reforms.

\section{Note}

1 Contrary to other countries, Dutch social benefits are disbursed as gross incomes, so subject to income tax.

\section{References}

Atkinson, A. B. (1996) 'The case for a participation income', Political Quarterly, 67, 1, 67-70.

Bohnet, I., Frey, B. S. and Huck, S. (2001) 'More order with less law: on contract enforcement, trust and crowding', The American Political Science Review, 95, 1,131-44.

Deci, E. L. and Ryan, R. M. (1985) Intrinsic Motivation and Self-Determination in Human Behavior, New York: Plenum. 
Fehr, E. and Schmidt, K. M. (2003) 'Theories of fairness and reciprocity: evidence and economic applications', Advances in Economics and Econometrics, Econometric Society, Eighth World Congress, 1, 208-57.

Frey, B. S. and Jegen, R. (2001) 'Motivation crowding theory', Journal of Economic Surveys, 15, 5, 589-611.

Goodin, R. E., Headey, B., Muffels, R. and Dirven, H.-J. (1999) The Real Worlds of Welfare Capitalism, Cambridge: Cambridge University Press.

Groot, L. F. M. (2004) 'Chapter 4: why launch a basic income experiment?' in Basic Income, Compensatory Justice and Unemployment, Boston: Kluwer Academic Publishers.

Groot, L. and van der Veen, R. (2000) 'Clues and leads in the policy debate on basic income in the Netherlands', in R. van der Veen and L. Groot (eds.), Basic Income on the Agenda: Policy Objectives and Political Chances, Amsterdam: Amsterdam University Press, 197-223.

Hemerijck, A. (2013) Changing Welfare States, Oxford: Oxford University Press.

Hemerijck, A. (ed.) (2017) The Uses of Social Investment, Oxford: Oxford University Press.

Mani, A., Mullainathan, S., Shafir, E. and Zhao, J. (2013) 'Poverty Impedes Cognitive Function', Science, 341, August, 976-80.

Maydell, v. B., Borchardt, K., Henke, K.-D., Leitner, R., Muffels, R., Quante, M., Rauhala, P.-L., Verschraegen, G. and Zukowski, M. (2006) Enabling Social Europe, Berlin, Heidelberg, Nework: Springer.

McFarland, K. (2017) 'Overview of current basic income related experiments', BIEN Network Report, October.

Morel, N., Palier, B. and Palme, J. (2012) Towards a Social Investment Welfare State? Ideas, Policies and Challenges, Bristol: The Policy Press.

Muffels, R. (ed.) (2008) Flexibility and Employment Security in Europe. Labour Markets in Transition, Cheltenham, UK and Northampton, MA, USA: Edward Elgar.

Muffels, R. (2014) 'Berghman's social security definition: challenging the goals and values of welfare states', in W. Oorschot, H. Peeter and K. Boos (eds.), Invisible Social Security Revisited. Essays in Honour of Jos Berghman, Tielt: Lannoo Publishers, 109-26.

Mullainathan, S. and Shafir, E. (2013) Scarcity - The True Cost of Not Having Enough. London: Penguin Books.

Pierson, C., Castles, F.G. and Naumann, I. K. (2014) The Welfare State Reader, Cambridge: Polity Press.

Roelofs, G. and D. van Vuuren (2011) 'The decentralisation of social assistance and the rise of disability insurance enrolment', CPB Discussion Paper 185, The Hague: CPB Netherlands Bureau for Economic Policy Analysis.

Ryan, R. M., Kuhl, J. and Deci, E. L. (1997) 'Nature and autonomy: an organizational view of social and neurobiological aspects of self-regulation in behavior and development', Development and Psychopathology, 9, 4, 701-28.

Sen, A. K. (2004) 'Capabilities, lists, and public reason: continuing the conversation', Feminist Economics, $10,3,77-80$.

Sen, A. K. (2009) The Idea of Justice, London, Allen Lane.

Schmid, G. and Gazier, B. (eds.) (2002) The Dynamics of Full Employment: Social Integration Through Transitional Labour Markets, Cheltenham: Edward Elgar, 233-74.

Soentken, M., van Hooren, F. and Rice, D. (2017) 'The impact of social investment reforms on income and activation in the Netherlands', in A. Hemerijck (ed.), The Uses of Social Investment, OUP Oxford, Kindle Edition, 475.

Thaler, R. H. and Sunstein, C. R. (2008) Nudge: Improving Decisions about Health, Wealth, and Happiness, New Haven, Conn.: Yale University Press.

van Parijs, P. (2004) 'Basic income, a simple and powerful idea for the twenty-first century', Politics and Society, 32, 1, 7-39.

Widerquist, K. (forthcoming) The Devil's in the Caveats: A Critical Analysis of Basic Income Experiments for Researchers, Policymakers, and Citizens, Palgrave Macmillan. 